\title{
Commentary
}

\section{Developing CAM Research Capacity for Complementary Medicine}

\author{
George Lewith ${ }^{1}$, Marja Verhoef ${ }^{2}$, Mary Koithan ${ }^{3}$ and Suzanna M. Zick ${ }^{4}$ \\ ${ }^{1}$ Complementary Medicine Research Unit, University of Southampton, UK, ${ }^{2}$ Department of Complementary Medicine, \\ University of Calgary, Canada, ${ }^{3}$ Program in Integrative Medicine and the College of Nursing, University of Arizona, \\ Tucson, AZ, USA and ${ }^{4}$ Department of Family Medicine, Michigan Integrative Medicine, University of Michigan, MI, USA
}

\begin{abstract}
This article describes initiatives that have been central to the development of complementary and alternative medicine (CAM) research capacity in the United Kingdom, Canada and the United States over the last decade. While education and service delivery are essential parts of the development of CAM, this article will focus solely on the development of research strategy. The development of CAM research has been championed by both patients and politicians, primarily so that we may better understand the popularity and apparent effectiveness of these therapies and support integration of safe and effective CAM in health care. We hope that the perspective provided by this article will inform future research policy.
\end{abstract}

Keywords: CAM-research-strategy-US-UK-Canada

\section{Introduction}

Over the last 10 years, complementary and alternative medicine (CAM) research capacity has developed apace with several leading research departments, now offering an established research and research training environment (1).

While CAM is not new, it is now being addressed in a much more formal way than before, particularly in North America. We currently have a number of indexed, peer-reviewed journals, such as Complementary Therapies in Medicine, the Journal of Alternative and Complementary Medicine, Forschende Komplementärmedizin and Alternative Therapies in Health and Medicine, eCAM and Planta Medica with growing impact factors. We also have an exponential increase in research funding, and the very early development of consistent and coherent research capacity, both in North America and in the United Kingdom. This article maps the history and politics of the development of CAM in the United States, the United Kingdom and Canada and provides a social and political perspective.

In the early days, the term CAM was commonly used, and the term is still very prevalent in the United Kingdom, Canada

For reprints and all correspondence: Dr George Lewith, Complemementary Medicine Research Unit, Aldermoor Health Centre, Aldermoor Close, Southampton SO16 5ST UK. Tel: +44 2380241073 Fax: +44 238070 1125. E-mail: g13@soton.ac.uk and the United States However, the terms integrative medicine or integrated health care are becoming increasingly common and suggest a stronger focus on integrating these different philosophies. The term CAM may be seen as representative of early development in this field. We do believe, however, that in its current use, the differences between CAM and integrative medicine are less substantial than the terms suggest. A summary of the current situation is described in Table 1.

\section{The United Kingdom}

\section{A Beginning}

This brief summary takes into account the developments over a 25 year period. The Research Council for Complementary Medicine was established in 1982 with the primary aim of raising charitable money in order to develop both research capacity and a research agenda within complementary medicine as part of a UK university research strategy. It was initially conceived as a 'complementary medical, Medical Research Council' and has acted as a consistent and sustaining charitable supporter of the UK CAM research agenda over the last 25 years. It was responsible for the first CAM research fellowship in the mid-1980s at Glasgow university, the publication of the first CAM research journal; Complementary

(C) The Author (2006). Published by Oxford University Press. All rights reserved.

The online version of this article has been published under an open access model. Users are entitled to use, reproduce, disseminate, or display the open access version of this article for non-commercial purposes provided that: the original authorship is properly and fully attributed; the Journal and Oxford University Press are attributed as the original place of publication with the correct citation details given; if an article is subsequently reproduced or disseminated not in its entirety but only in part or as a derivative work this must be clearly indicated. For commercial re-use, please contact journals.permissions@oxfordjournals.org 
Medical Research which has subsequently transformed into Complementary Therapies in Medicine and is now published by Elsevier, as well as one of the first complementary medical databases (CISCOM).

\section{The Emergence of a Research Strategy}

Almost all these developments were at least a decade ahead of their time and forged an innovative and largely independent CAM research agenda in the United Kingdom. This primarily, but by no means exclusively, involved physicians both practicing and researching within CAM and encompassed the development of research within acupuncture, homeopathy and manipulative medicine, in particular chiropractic. Other than for some interest in Glasgow, Southampton and in London through the Royal London Homoeopathic Hospital, there was little formal university or NHS support for these research initiatives. However, in the mid-1990s, the Foundation for Medicine, in conjunction with the Prince of Wales and with the support of the British Medical Association and the Royal College of Physicians, among other medical institutions, began to develop a clear five year strategic plan that encompassed the central issues within CAM. These included the development of a strategic plan to improve both research capacity and research output. The enablement and delivery of complementary and integrated medicine within the NHS, an educational initiative, primarily directed at medical undergraduates and postgraduates developing a better and more coherent understanding of CAM which had initially been suggested by the BMA and was substantively supported by the UK General Medical Council and the Foundation for Integrated Medicine (2). The fourth arm to the Foundation's initiative involved the regulation of complementary medical practice by both doctors and non-medically qualified practitioners within the United Kingdom. The Foundation for Integrated Medicine was re-born as the Prince of Wales's Foundation for Integrated Health in 2000 but still fulfils much the same functions, in particular with respect to the government's increasing regulatory agenda as far as complementary medical practitioners are concerned.

\section{The Department of Health Response and Subsequent Strategic Development}

The remit of this article is, however, to consider the research agenda rather than education, delivery and regulation. As a consequence of the Foundation's five year strategic plan, the UK Department of Health set up a House of Lords' Select Committee headed by Lord Walton who produced, over a period of one year, a very substantive document setting the agenda for regulation and research within CAM (3). The Department of Health responded promptly and efficiently with the establishment of both a formal regulatory process and a program of fellowships at doctoral and post-doctoral levels for complementary medicine. These fellowships were administered by the National Capacity Building Awards' Committee within the Department of Health and involved paired doctoral and post-doctoral fellowships awarded in 2003 and 2004 to universities who were assessed as having the capacity to sustain and develop a CAM research agenda. Of these paired awards, 9 have been made involving 18 substantive university posts within the United Kingdom. As a consequence of changes within the Department of Health Capacity Building Awards' Committee, the CAM committee has now been merged with the other award committees and is part of the overall NHS Research and Development capacity building exercise. There are now no 'specific CAM awards' but CAM is a recognized part of the research agenda within the United Kingdom and CAM-specific projects are welcomed by the National Capacity Building Awards' Committee. This has enabled a substantial process of academic development within CAM, in the UK university structure.

The present state of UK CAM research encompasses 14 universities who have more than 2 substantially part-time or full-time researchers engaged in CAM research in the United Kingdom. These are by no means exclusively within medical schools but are distributed between schools of nursing, physiotherapy and medical schools as well as research within departments of psychology and social sciences. At the present time and undoubtedly as a consequence of the Prince of Wales's Foundation for Integrated Health and Department of Health initiatives allied with the Research Council for Complementary Medicine's support, complementary medicine research within the United Kingdom is developing apace. Exeter, Leeds, Thames Valley, Westminster and Northampton universities are all led by researchers with professorial appointments, another example of the academic respect which this area is slowly beginning to develop.

\section{Canada}

\section{The Beginning}

While a small number of individual researchers in Canada have been investigating CAM for decades, it was not until the late nineties that a CAM research community started to develop. This was largely due to support from Health Canada [(the Federal Department 'responsible for helping Canadians maintain and improve their health', (4)], through funding a number of initiatives, via the Natural Health Products Directorate (NHPD) and the Health Human Resource Strategies Division (HHRSD). The HHRSD commissioned a comprehensive report about the state of CAM in Canada (5) as well as a widely read collection of papers examining the role of CAM in health care in Canada (6). It was around this time (1999) that plans to establish the Canadian Institutes of Health Research (CIHR), the major agency responsible for funding health research in Canada, were taking shape and a large group of CAM researchers and practitioners met for the first time to write a proposal to establish a Canadian Office for Complementary and Alternative Health Care under the auspices of the CIHR. Although the group was not successful, this meeting formed 
the foundation for discussing strategies to further CAM research in Canada (Table 1).

One of the first priorities this group identified was to 'develop a cadre of multidisciplinary, accomplished and appropriately trained investigators ... to work towards the unique needs of this emerging area' (7). This goal was again facilitated by Health Canada, whose efforts were mostly targeted at CAM practitioners and academic (basic and applied sciences) researchers and resulted in emphasizing the importance of CAM research literacy and capacity building, research priority setting and identification of the need for formal research networks in Canada. While progress was made in all areas, the gap between basic (e.g. pharmacology, toxicology) and applied scientists (e.g. sociologists, epidemiologists) was never closed. It appears that for various reasons, NHP basic science researchers do not identify with the CAM label.

\section{Research Network Building}

Several local and provincial networks were developed between 2000 and 2002, followed by the development of the Canadian Interdisciplinary Network for CAM research (IN-CAM), funded by the CIHR and Health Canada's Natural Health Products Directorate, the Natural Health Products Research Society of Canada (NHPRSC), also with the support of Health Canada's Natural Health Products Directorate and the Advanced Foods and Materials Network (AFMnet), all in 2003. While IN-CAM focuses on health services and policy research, methodological research and knowledge transfer, the NHPRSC is purely NHP research based. Collegial relations and some overlap between these organizations exist. However, this development effectively means that NHP research is separated from that of social sciences and health services. Last, investigators interested in pediatrics and CAM research have joined forces and established the Canadian Pediatric Complementary and Alternative Medicine Network (PedCAM). At this point, only IN-CAM is actively involved in organizing seed funding and student funding competitions and several of its members have jointly developed CAM research projects. However, owing to IN-CAM's limited term of funding ( 5 years), its sustainability is not certain.

\section{Education and Funding}

Canada has no formal training programs in CAM research, however, several universities across the country have informally established a reputation of CAM research and training, usually based on the presence of (one) researcher with a professional appointment in core academic fields such as epidemiology, sociology or pharmacy and a research program in the field of CAM research (e.g. Calgary, Edmonton, Saskatoon, Toronto, Montreal, Ottawa and Quebec City). Formal funding competitions, while limited, have only been organized by the Natural Health Products Research Program (Health Canada). While no major granting agencies have organized CAM-specific research granting competitions, CAM researchers appear to be reasonably successful in open competitions in the last 5-10 years. In addition, several private foundations (e.g. the Lotte \& John Hecht Memorial Foundation and the Hospital for Sick Children Foundation) have consistently funded Canadian CAM researchers.

\section{Where Next?}

Where does that leave Canada? Research capacity building in CAM research will continue slowly through the training of researchers in academic departments with expertise in fields other than CAM (e.g. epidemiology, sociology, pharmacology, etc.). While CAM-specific funding agencies or programs are not likely to occur in the near future, the increasing sophistication of CAM researchers and the public pressure for more information about CAM products and therapies should ensure that CAM research continues to be funded through mainstream funding opportunities. Although it is not likely that the schism between CAM social science researchers and NHP basic science researchers will disappear, networking will continue to be a key defining feature of Canadian CAM research and is likely to grow more internationally over time.

\section{The United States}

\section{Early History}

Similar to the development of a CAM research community in Canada, formal institutional support of research into complementary and alternative health care began approximately 15 years ago in the United States. Prior to the establishment of the Office of Alternative Medicine (OAM) within the National Institutes of Health (NIH) in the early 1990s, researchers interested in holistic healing, complementary therapies and integrative or indigenous healing systems applied to other institutes within the NIH. Alternatively, researchers could access funding from private foundations dedicated to the ongoing inquiry about holistic/alternative healing techniques (8-10).

\section{Formalizing CAM Research within the NIH}

Mechanisms to develop investigators dedicated to the science of integrative/complementary medicine and whole systems/ person healing and building an increased research capacity in this field were formalized in the US when Congress established the Office of Alternative Medicine (OAM) within the $\mathrm{NIH}$ (11). This effort was galvanized by Eisenberg's initial survey demonstrating the high level of interest, prevalence of use and out-of-pocket expenditures on CAM by the US population (12). In 1993, the OAM funded the first extramural grant projects and over the ensuing 12 years, the US federal government through NIH has created programs to focus the development of 'interdisciplinary CAM research conducted in academic institutions in the US' (11). In 1998, the National Center for Complementary and Alternative Medicine (NCCAM) was created as an independent component of 


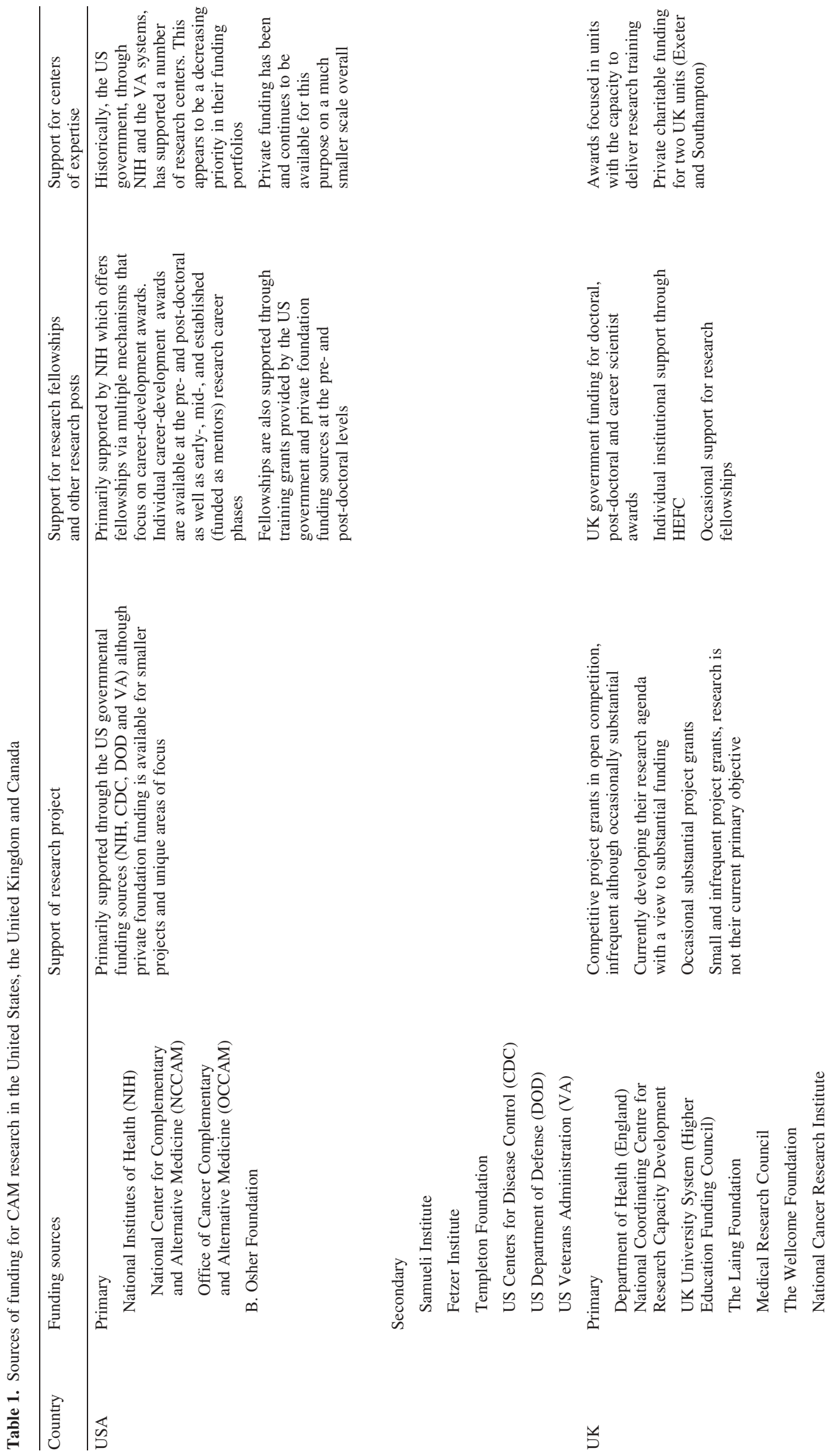



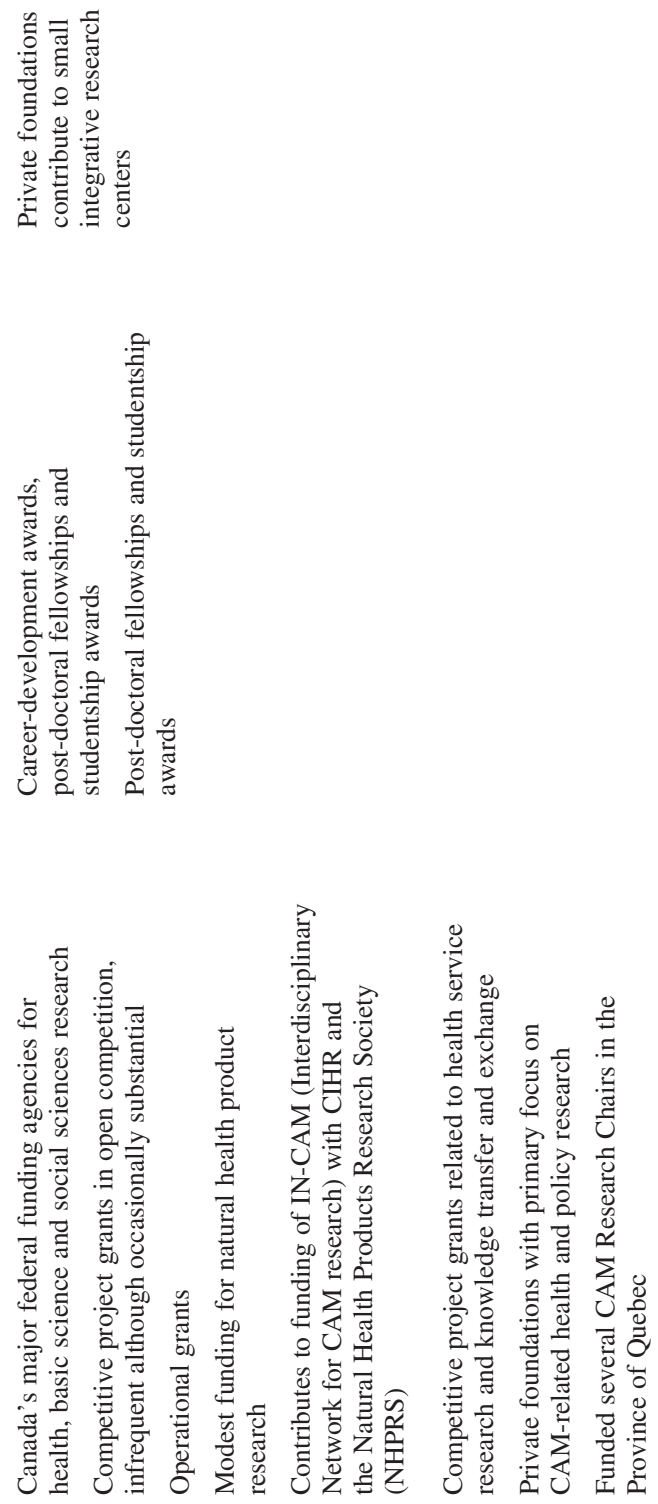
the NIH. As such, NCCAM was given broad financial and administrative authority for its operations and responsibility for the review and funding of its grants and contracts, establishing research priorities for CAM and whole systems research and the development of scientists who are able to move the science forward (11).

Since that time, NCCAM's budget and its sphere of influence has grown substantially. In 2005, NCCAM's budget reached approximately $\$ 123$ million USD, employing over 90 full-time staff members. Currently, NCCAM funds and supports a host of research-related activities for the scientific, practice and lay communities in the US and abroad, including a comprehensive Internet source of research-based information on CAM (CAM on PubMed); intramural and extramural competitive investigator-initiated research awards; individual pre-doctoral and post-doctoral individual research training fellowships; career-development fellowships; and institutional exploratory centers and institutional research development/ training center awards, all of which have supported growth in CAM research capacity and productivity.

NCCAM's primary funding focus through the late 1990s was primarily Phase II and III clinical trials, supporting large centers capable of engaging in sophisticated large clinical trials. Many of these first centers could be found in medical schools or academic health sciences centers, although several interdisciplinary centers were also funded. Since 2000, centers that focus on developing foundational or basic knowledge in energetic/biofield science, nutritional/dietary supplements and botanicals and manipulative therapies have also been funded. These centers have generally expanded beyond clinical trials to include pre-clinical and basic science research. Today there are approximately 30 distinct 'nodes' of CAM research; universities, medical centers/health care delivery systems and CAM research/educational consortia that have or have had NCCAM center grants.

\section{Current US Initiatives and Challenges}

The 2005-09 NCCAM five year strategic plan presents a refined direction and vision for the development and support of CAM research in the US. While the first plan (2001-05) clearly stated the need for and intention to develop training programs that increased the number, quality and diversity of CAM researchers, the second plan now explicitly identifies its priority to be in support of research 'geared to elucidating mechanisms of action underlying CAM practices' (13). While NCCAM continues to support Phase II clinical trials, NCCAM has also stated its intent to decrease CAM clinical research funding to focus on basic and pre-clinical research, addressing mechanism of action, bringing its budget into alignment with other NIH components. As much as $80 \%$ of NCCAM's budget has historically been invested in testing the efficacy and safety of CAM practices already used by the US population, while the $\mathrm{NIH}$ norm is $\sim 33 \%$. How this will translate into the portfolio of funded studies is yet to be seen.
What remains less clear with this new document is NCCAM's ongoing commitment to the development of research scientists. With respect to the development of new scientists, NCCAM now clearly identifies the need to focus on development of research skills CAM-trained professionals (13). In response, NCCAM has introduced both individual and institutional awards to support research education and initial project funding for CAM practitioners as well as the institutional research efforts of CAM-specific educational settings. Yet, the institutions with resources needed to support the development of these researchers (mentors and supportive research environments) are still the traditional university and academic medical centers; places where the CAM practitioner is not educated and does not practice. Traditional settings will have to step out of their historical and, at times, insular perspectives, providing opportunities outside of the traditional educational and training programs for these CAM providers. In turn, CAM educational settings will have to embrace the need to support research units with start-up funds. Dialogue across academic and practice settings (traditional and CAM) in the US must begin immediately to address these various training needs.

\section{What Might the Future Hold?}

The foundation of the International Society of Complementary Medicine Research (14) was an important step towards building an international CAM research community and was initially largely supported by the United Kingdom, Canada and the United States We all envision the future of CAM research as an important interdisciplinary and international research effort. Practitioners, both CAM and conventional, will need to build their research literacy and capacity, and researchers need to become more knowledgeable about CAM practices and/or include CAM practitioners on their teams. CAM research will positively impact conventional medicine, particularly in broadening its perspective and understanding of the contextual, relational and non-specific factors that affect health outcomes. Complementary medical interventions are generally very complex and our increasing understanding of this complexity and the underlying psychological and physiological models will very probably contribute substantially to our understanding of the equally complex and ill-understood interventions that occur in conventional medicine, such as the routine consultation within family practice. Maybe then, we will finally become one, good, medicine.

\section{Acknowledgments}

Dr Lewith's post is funded by a grant from the Rufford Maurice Laing Foundation. The authors wish to acknowledge Iris Bell, Professor, College of Medicine, University of Arizona, for her comments and assistance in the preparation of this manuscript and for her input on the US information. 


\section{References}

1. Lewith GT. Complementary medicine research unit. Evid Based Complement Altern Med 2005;2:399-407.

2. General Medical Council. Tomorrow's doctors. Recommendations on undergraduate medical education. London: GMC, 1993.

3. House of Lords' Select Committee on Science and Technology. 6th Report, Session 1999-2000. Complement Altern Med6; 2000.

4. Health Canada. Accessed at http://www.hc-sc.gc.ca/ahc-asc/index_e.html.

5. York University Centre for Health Studies Complementary and Alternative Health Practices and Therapies-A Canadian Overview. Canada: York University, 1999.

6. Health Canada. Perspectives on Complementary and Alternative Health Care: A collection of papers prepared for Health Canada. (Cat. No. H39-572/2001E). Ottawa, Ontario, Canada: Author, 2001.

7. Design for a Canadian Office for Complementary and Alternative Health Care. A White Paper for the Interim Governing Committee of the Canadian Institutes of Health Research. Submission to CIHR by Integrative Medicine and Health Network. December 20, 1999.

8. Bortoff J. A methodological review and evaluation of research on nurse-patient touch. In: Chinn P (ed). Anthology on Caring. New York: NLN Publications, 1991, 303-43.
9. Guzzetta C. Effects of relaxation and music therapy on patient in a coronary care unit with the presumptive diagnosis of Acute Myocardial Infarction. Heart Lung 1989;19:609-16.

10. Budzynski TH, Stoyya JM, Adler CS, Mullaney DJ. EMG biofeedback and tension headache: a controlled outcome study. Psychosom Med 1973;35:484-96.

11. The NIH almanac: National Center for Complementary Alternative Medicine. Accessed at http://www.nih.gov/about/almanac/organization/ NCCAM.htm.

12. Eisenberg DM, Kessler RC, Foster C, Norlock FE, Calkins DR, Delbanco TL. Unconventional medicine in the United States. Prevalence, costs, and patterns of use. New Engl J Med 1993;328:246-52.

13. NIH/NCCAM.Expanding horizons of health care: strategic Plan 2005-2009. Accessed at http://nccam.nih.gov/about/plans/2005/index. htm (2005)

14. Verhoef MJ. Founding the International Society of Complementary Medicine Research. Announcement. Evid Based Complement Altern Med 2004;1:111.

Received November 17, 2005; accepted February 13, 2006 


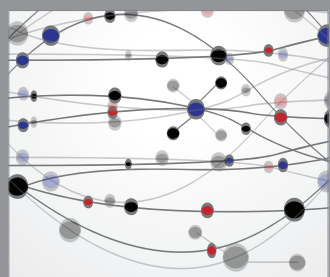

The Scientific World Journal
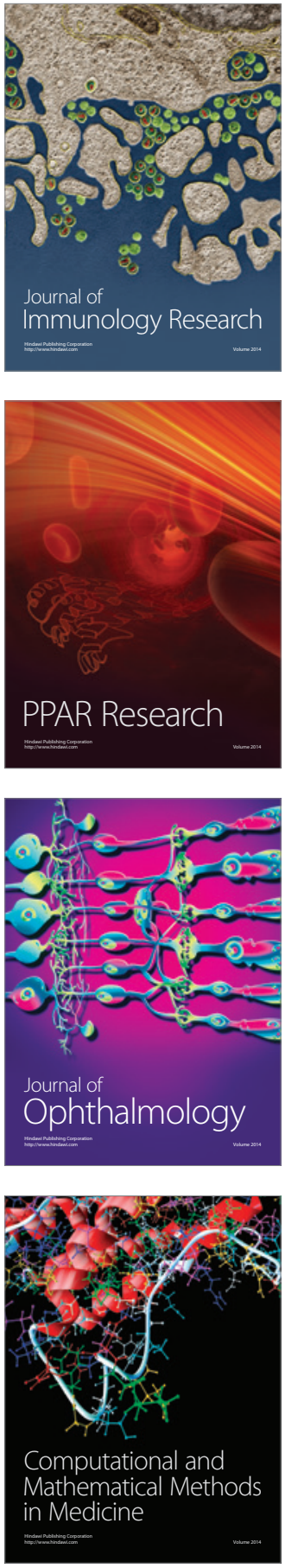

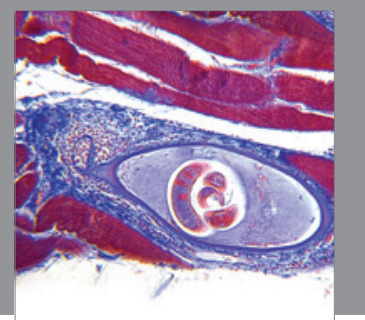

Gastroenterology

Research and Practice
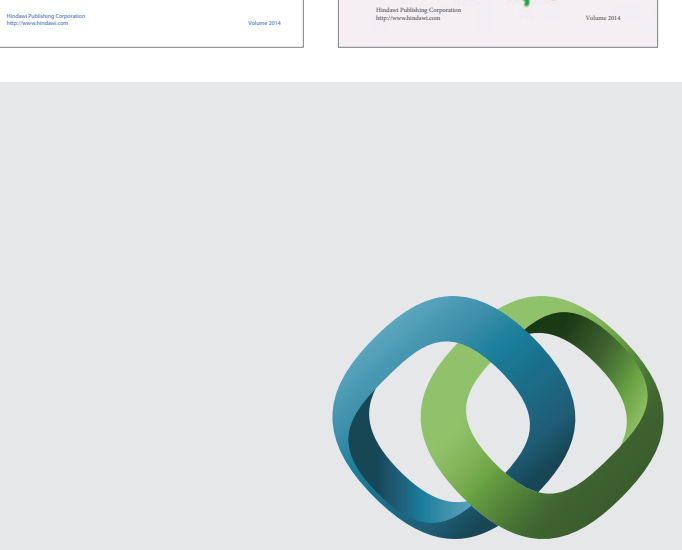

\section{Hindawi}

Submit your manuscripts at

http://www.hindawi.com
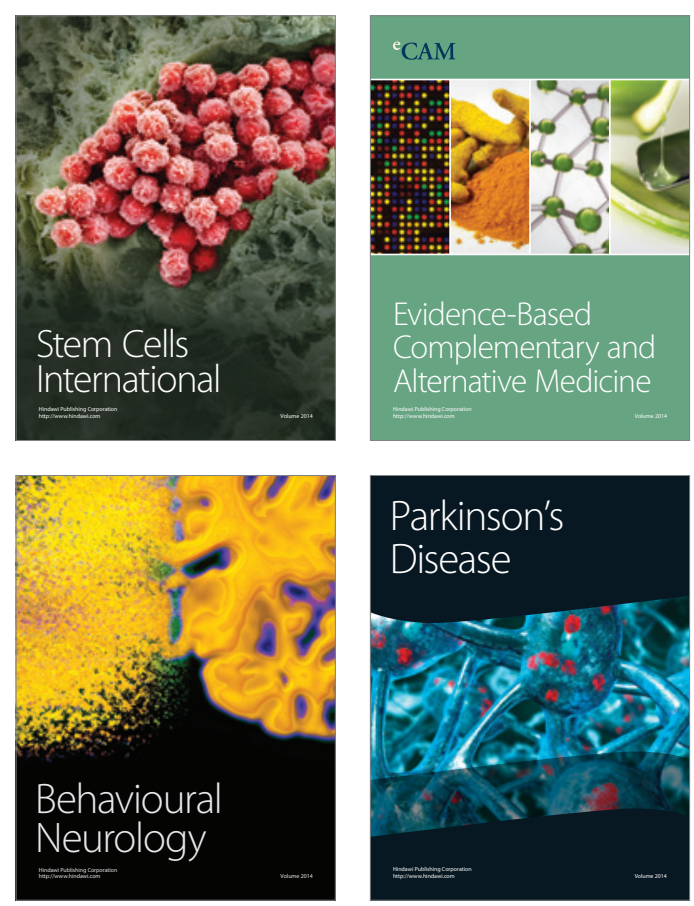

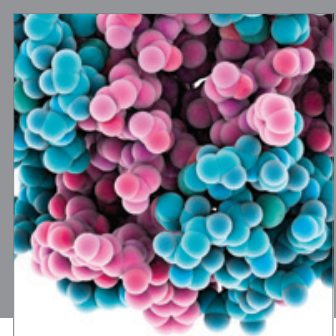

Journal of
Diabetes Research

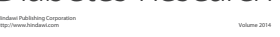

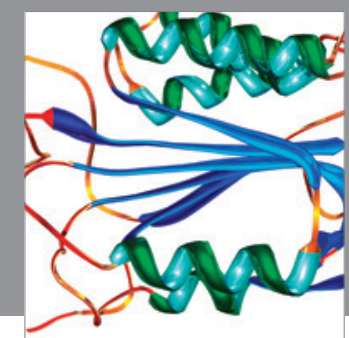

Disease Markers
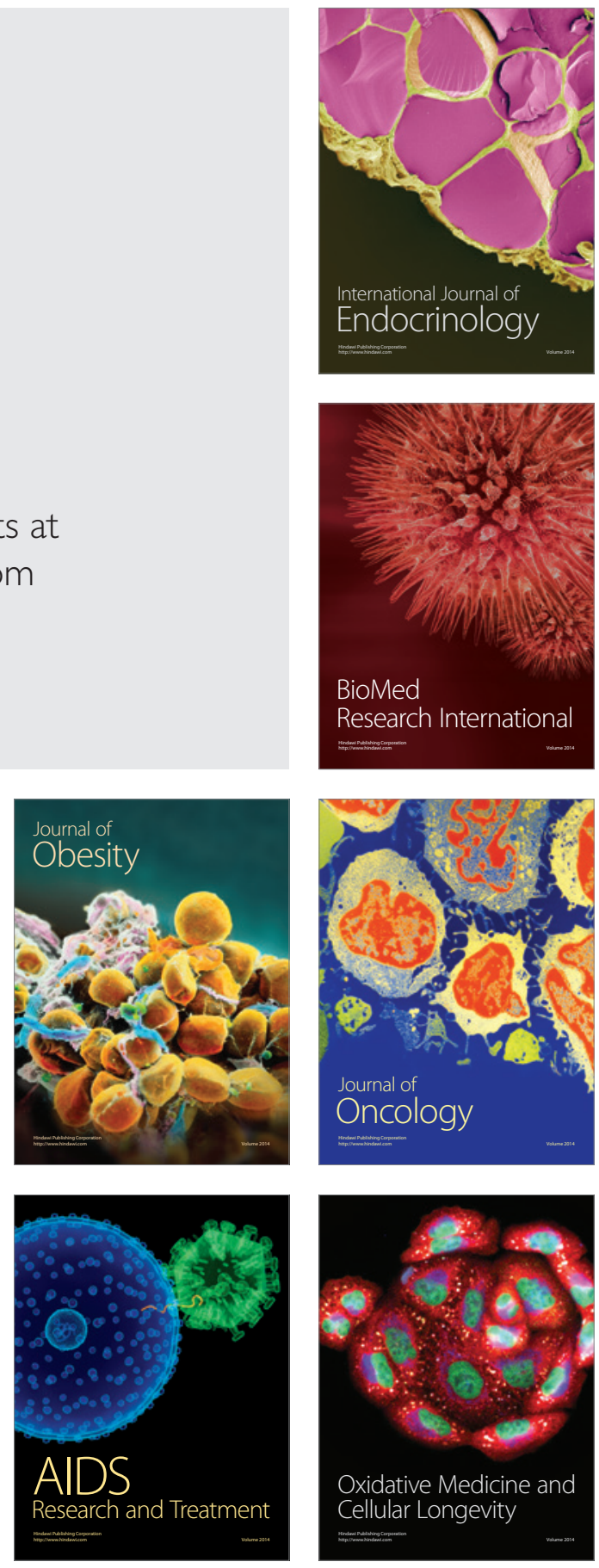